\title{
A fast and simple method to eliminate Cpn60 from functional recombinant proteins produced by E. coli Arctic Express
}

\author{
Lorène Belval $^{\mathrm{a}, \mathrm{b}}$, Arnaud Marquette ${ }^{\mathrm{c}}$, Pere Mestre ${ }^{\mathrm{a}, \mathrm{b}}$, Marie-Christine Piron ${ }^{\mathrm{a}, \mathrm{b}}$, Gérard Demangeat ${ }^{\mathrm{a}, \mathrm{b}}$, \\ Didier Merdinoglu ${ }^{\mathrm{a}, \mathrm{b}}$, Jean-François Chich ${ }^{\mathrm{a}, \mathrm{b}, *}$ \\ a INRA, UMR 1131 Santé de la Vigne et Qualité du Vin, F-68021 Colmar, France \\ ${ }^{\mathrm{b}}$ Université de Strasbourg, UMR 1131 Santé de la Vigne et Qualité du Vin, F-68000 Colmar, France \\ ${ }^{\mathrm{C}}$ UMR 7177, Institut de Chimie, F-67000 Strasbourg, France
}

\section{A R T I C L E I N F O}

\section{Article history:}

Received 22 October 2014

and in revised form 8 January 2015

Available online 3 February 2015

\section{Keywords:}

Recombinant protein

Arctic Express

Cpn60

IMAC

\begin{abstract}
A B S T R A C T
A frequent problem of recombinant protein production is their insolubility. To address this issue, engineered Escherichia coli strains like Arctic Express that produce an exogenous chaperone facilitating protein folding, have been designed. A drawback is the frequent contamination of the protein by chaperones. A simple method, using urea at a sub-denaturing concentration, allows unbinding of Cpn60 from expressed protein. This method was successfully used to purify 2 proteins, an enzyme and a viral protein. The enzyme was fully active. The nature of interaction forces between enzyme and Cpn60 was investigated. The method is likely applicable to purify other proteins.
\end{abstract}

(C) 2015 Elsevier Inc. All rights reserved.

\section{Introduction}

Escherichia coli has proved to be invaluable for heterologous protein production since many years [1]. Strategies for protein production have been extensively developed and numerous issues have been solved as shown by the development of vectors that facilitate cloning [2] as well as expression of toxic proteins [3], and strains allowing expression of proteins containing disulfide bridges, like Shuffle or Origami [4], or proteins that are prone to aggregate [5].

Overproduction of a protein by E. coli can result in production of aggregates or inclusion bodies despite the presence of a native complex system of chaperones [6,7]. This can sometimes be overcome by lowering the temperature after induction [8]. Another alternative is the use of strains expressing exogenous chaperones like Arctic Express which constitutively express 2 chaperones, Cpn10 and Cpn60 [9,10] from Oleispira antarctica, a psychrophilic bacterium. Both chaperones assist in the correct folding of proteins of interest and avoid, or limit, accumulation of inclusion bodies [11-13].

A disadvantage of Arctic Express is that chaperones often copurify with the protein of interest, and could potentially modify the activity and/or the stability of the product. Moreover, due to

* Corresponding author at: INRA, UMR 1131 Santé de la Vigne et Qualité du Vin, F-68021 Colmar, France. Tel.: +33 (0)3 892249 41; fax: +33 (0)3 89224933.

E-mail address: jfchich@colmar.inra.fr (J.-F. Chich). the contamination, protein crystallization for further structural studies is not feasible. There are reports of protocols to eliminate contaminant chaperones $[14,15]$ but they remain adapted to specific proteins and are not necessarily applicable to others.

We used Arctic Express to produce an endoglucanase from Vitis. We found that after IMAC ${ }^{1}$ purification, the enzyme remained greatly contaminated by Cpn60. A previously published protocol that was assessed to eliminate chaperones, was inefficient [15]. Here, we develop a new protocol using a sub-denaturing urea concentration and show that a simple wash allows to purify the protein of interest to homogeneity. Next, we study the impact of this wash on enzymatic activity and show an improvement following this treatment. Finally, we successfully apply this protocol to a second protein, a viral movement protein [16,17].

\section{Materials and methods}

Complete Protease inhibitors (without EDTA) were purchased from Roche Diagnostics (Meylan, France). Ampicillin, ATP and Laminarin were from Sigma-Aldrich (Saint-Louis, Missouri, USA). NiTED Protino kit was obtained from Macherey-Nagel (Düren, Germany). LR and BP clonases were from Invitrogen (Carlsbad, CA, USA). Miniprep kit used to purify plasmids was from Qiagen (QIA-

\footnotetext{
${ }^{1}$ Abbreviations used: DLS, Dynamic Light Scattering; GFLV, Grapevine Fanleaf Virus; IMAC, Immobilized Metal Affinity Chromatography; MP, Movement Protein.
} 
gen Gmbh, Hiden, Germany). E. coli Arctic Express strain was purchased from Agilent Technologies (Palo Alto, CA, USA).

Wash buffer from the Ni-TED Protino Macherey-Nagel kit was termed LEW $1 \times$ (Lysis-Equilibration-Wash Buffer: $300 \mathrm{mM} \mathrm{NaCl}$, $50 \mathrm{mM} \mathrm{NaH} \mathrm{PO}_{4} \mathrm{pH}$ 8.0). Other wash buffers compositions are detailed in Fig. 1 and Table 1. Elution buffer was from the Macherey-Nagel kit (Protino Ni-TED).

\section{DLS measurements}

DLS measurements were performed on a Zetasizer Nano-S system (Malvern Instruments, Worcestershire, UK). $40 \mu \mathrm{L}$ of samples were transferred in a low volume quartz cuvette (Hellma Analytics, Müllheim, Germany) and placed in the thermally jacketed sample holder $\left(T=25^{\circ} \mathrm{C}\right)$ of the instrument. All the measurements were performed at a minimum concentration of $1.6 \mathrm{mg} \mathrm{mL}^{-1}$ ensuring a good signal to noise ratio for the recordings. The calibration of the apparatus was performed by measuring the size of $60 \mathrm{~nm}$ polymer microspheres suspended in pure water (Duke Scientific, Palo Alto, CA). The volume versus size distributions were deduced from the analysis of the recorded correlation functions, using a multiple narrow modes algorithm implemented in the DTS-Malvern software.

\section{Gene cloning}

The primers used in this work are available upon request.

\section{Endoglucanase}

The coding region of a Vitis vinifera putatively secreted endoglucanase (UniProtKB: F6HLL8) was amplified from cDNA from $V$. vinifera leaves using PHUSION High-Fidelity polymerase (Finnzymes, Thermo Scientific, Waltham, MA) according to manufacturer's instructions and primers with overhangs containing sites for restriction enzymes. The PCR product was digested and directionally cloned into vector pBIN61 digested with the same enzymes. Identity of the clone was verified by sequencing. This clone was used to PCR-amplify the endoglucanase coding sequence excluding any putative signal sequence (i.e. signal peptide). The resulting PCR product was ligated by recombination in pDONR207 plasmid, using BP clonase. E. coli DH5 $\alpha$ were transformed and grown in LB-Ampicillin $\left(100 \mu \mathrm{g} \mathrm{mL}^{-1}\right)$. Plasmid with insert was purified (MiniPrep, QIAGen) and sequenced. The endoglucanase gene was transferred from pDONR207 to pHGWA [2] by recombination, using LR clonase according to manufacturer's instructions. Plasmid was purified from $E$. coli $\mathrm{DH} 5 \alpha$ and, after sequence verification, used to transform E. coli BL21(DE3) and Arctic Express (Agilent Technology). Positive clones were grown and kept frozen at $-80^{\circ} \mathrm{C}$.

\section{Viral MP}

The coding region for the GFLV movement protein was amplified by PCR from a full-length cDNA clone derived from the GFLV-F13 RNA2 (GenBank accession number: NC_003623). The resulting PCR product was ligated by recombination in pDONR/ Zeo plasmid, transferred to pHGWA and introduced to Arctic Express as described above for endoglucanase. The MP amino-acid sequence has the UniProtKB accession number P18474 [258-605], except the residues Phe ${ }^{308}$ and $\mathrm{Glu}^{309}$ which are modified into a Lys and a Gln, respectively [18].

\section{Protein production}

Bacteria were grown according to manufacturer's instruction. Briefly, $2 \mathrm{~mL}$ overnight culture was transferred into $200 \mathrm{~mL}$ of LB containing ampicillin $\left(100 \mu \mathrm{g} \mathrm{mL}^{-1}\right)$ and chloramphenicol
A

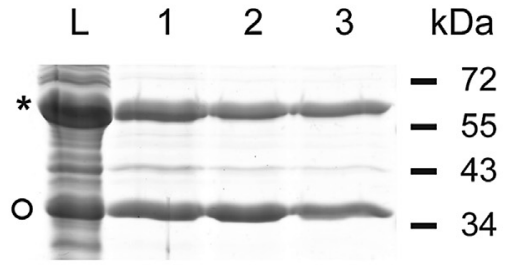

B

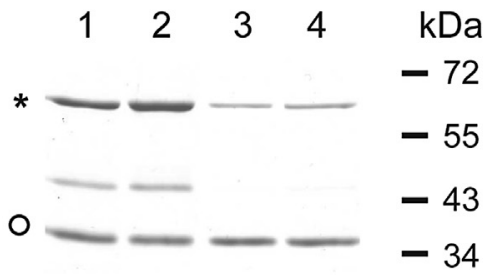

C

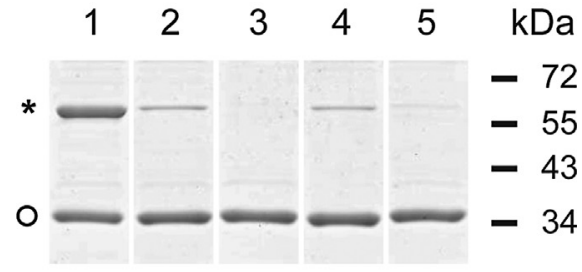

D

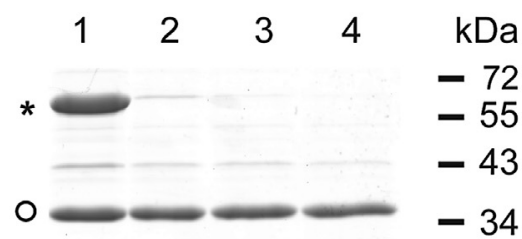

E

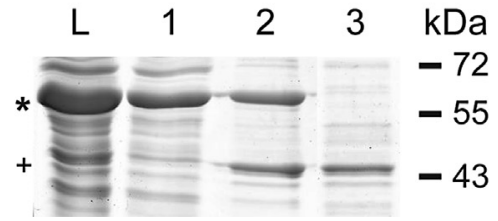

Fig. 1. SDS-PAGE of endoglucanase and MP stained with Coomassie colloidal Blue of fractions eluted from IMAC column after wash with different buffer compositions. (A) lane L: bacterial lysate, soluble proteins; lane 1: Wash with LEW1x kit buffer; lane 2: Wash with $\mathrm{NaCl} 0.5 \mathrm{M}$, Imidazole $10 \mathrm{mM}$, Tris $20 \mathrm{mM} \mathrm{pH}$ 6.8; lane 3: Wash with $\mathrm{NaCl}$ $1 \mathrm{M}$, Imidazole $20 \mathrm{mM}$, Tris $20 \mathrm{mM}$ pH 6.8. Cpn60 is indicated by* and endoglucanase by o. (B) lane 1: Wash with $\mathrm{KCl} 150 \mathrm{mM} / \mathrm{ATP} 10 \mathrm{mM} / \mathrm{MgCl}_{2} 10 \mathrm{mM}$; lane 2: Wash with $\mathrm{KCl} 150 \mathrm{mM}, 0.05 \%$ glucose; lane 3: Wash with $\mathrm{KCl} 150 \mathrm{mM}, 1 \mathrm{mg} \cdot \mathrm{mL}^{-1}$ laminarin; lane 4: Wash with $\mathrm{KCl} 150 \mathrm{mM}$. All solutions were buffered with $20 \mathrm{mM}$ Tris $\mathrm{pH} 6.8$ Cpn60 is indicated by * and endoglucanase by o. (C) lane 1: Wash with LEW 1x; lane 2: wash with imidazole $25 \mathrm{mM}, 20 \mathrm{mM}$ Tris- $\mathrm{HCl} \mathrm{pH} \mathrm{6.8}$; lane 3: wash with $2 \mathrm{M}$ urea, $20 \mathrm{mM}$ Tris- $\mathrm{HCl} \mathrm{pH} \mathrm{6.8;} \mathrm{lane} \mathrm{4:} \mathrm{wash} \mathrm{with} 2 \mathrm{M}$ urea, $20 \mathrm{mM}$ Tris- $\mathrm{HCl}$ pH 6.8, $10 \mathrm{mM}$ ATP, $10 \mathrm{mM} \mathrm{MgCl}_{2}$; lane 5: wash with previous buffer supplemented with $5 \mathrm{mM}$ imidazole. Cpn60 is indicated by * and endoglucanase by o. (D) Effect of increasing urea concentration on Cpn60 elimination. lane 1: Wash with LEW 1x; lane 2: Wash with $1 \mathrm{M}$ urea, Tris $20 \mathrm{mM} \mathrm{pH}$ 6.8; lane 3: wash with $1.5 \mathrm{M}$ urea, $20 \mathrm{mM}$ Tris pH 6.8; lane 4: wash with $2 \mathrm{M}$ urea, $20 \mathrm{mM}$ Tris $\mathrm{pH} 6.8$. Cpn60 is indicated by * and endoglucanase by o (E) SDS-PAGE of viral movement protein (MP) stained with Coomassie colloidal Blue. Lane L: bacterial lysate; lane 1: Flow-through fraction; lane 2: Elution fraction, after LEW 1x wash, contains MP and Cpn60; lane 3: Elution after wash with $2 \mathrm{M}$ urea, $20 \mathrm{mM}$ Tris- $\mathrm{HCl}$ pH 6.8. MP is no longer contaminated by Cpn60. Cpn60 is indicated by * and MP is indicated by + 
Table 1

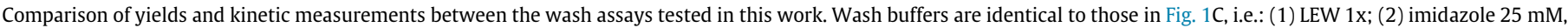

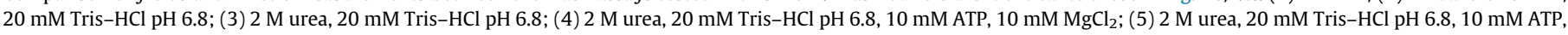
$10 \mathrm{mM} \mathrm{MgCl}, 5 \mathrm{mM}$ imidazole.

\begin{tabular}{|c|c|c|c|c|}
\hline Wash buffer & Proteins $(\mu \mathrm{g})$ & Specific activity $^{1}$ (nkat.ng $^{-1}$ ) & Total activity ( $\mu$ kat) & Purity (\%) \\
\hline 1 & 107 & $22 \pm 0.13$ & 2.35 & 44 \\
\hline 2 & 80.5 & $32 \pm 0.22$ & 2.58 & 80 \\
\hline 3 & 81 & $34 \pm 0.25$ & 2.75 & $>98$ \\
\hline 4 & 99 & $28.3 \pm 0.1$ & 2.8 & 74 \\
\hline 5 & 98.7 & $30 \pm 0.13$ & 2.96 & 87 \\
\hline
\end{tabular}

${ }^{1}$ Specific activities are means \pm standard deviations of 3 measurements.

$\left(50 \mu \mathrm{g} \mathrm{mL} \mathrm{m}^{-1}\right)$ and grown for $3 \mathrm{~h}$ à $28^{\circ} \mathrm{C}$. They were placed at $10^{\circ} \mathrm{C}$ for $1 \mathrm{~h}$ and protein production was induced by addition of $1 \mathrm{mM}$ IPTG, for $24 \mathrm{~h}$ at $10^{\circ} \mathrm{C}$. Bacteria were collected by centrifugation (6000g, $10 \mathrm{~min}$ ), washed with cold PBS buffer, again centrifuged and suspended in $1 / 100$ culture volume of PBS with protease inhibitors. They were then disrupted using a Branson sonifier 250 (Emerson, Saint-Louis, MO, USA) until clarification, typically $3 \times 30 \mathrm{~s}$. Cell fragments were pelleted by $10 \mathrm{~min}$ of centrifugation at $12,000 \mathrm{~g}$. Supernatant was collected, aliquoted and frozen at $-20^{\circ} \mathrm{C}$.

\section{Protein purification}

Proteins were purified using IMAC columns (Ni-TED Protino kit), either according to manufacturer's instructions, or to the modifications described in this article. Columns were equilibrated first with LEW $1 \times$ buffer before bacterial lysate was loaded. To ensure optimal binding of proteins, the recovered flow-through was loaded thrice. Wash assays were performed with 5 column volumes of wash buffers whose composition is shown in Fig. 1 and Table 1 legends, followed by 5 volumes of the LEW $1 \times$ buffer. Proteins were eluted with elution buffer, and collected as 5 fractions of $250 \mu \mathrm{L}$ each. Protein concentration was determined by measuring the absorbance at $280 \mathrm{~nm}$ on a nanodrop ND-1000 spectrophotometer (Thermo Fisher Scientific, Waltham, MA). Fractions containing proteins were concentrated/dialyzed against PBS using Amicon Ultra-0.5 Centrifugal Filter Devices (cut-off: $10 \mathrm{kDa}$; Millipore). Fraction volume and protein concentration were measured by absorption at $280 \mathrm{~nm}$. Molar concentration was calculated using the theoretical molar absorptivity of the enzyme $\left(\varepsilon_{\mathrm{M}}=41,830 \mathrm{~L} \mathrm{~mol}^{-1} \mathrm{~cm}^{-1}\right)$.

For MP, the same protocol was used, except that after elution, proteins were precipitated by methanol/chloroform method, dried, and resuspended with sample buffer [19], before SDS-PAGE.

\section{Enzymatic activity measurements}

The standard assay for $\beta$-glucanase was performed at $37^{\circ} \mathrm{C}$ for $30 \mathrm{~min}$, using $1 \mathrm{mg} \mathrm{mL}^{-1}(171 \mu \mathrm{M})$ laminarin as a substrate in $0.1 \mathrm{M}$ sodium acetate buffer $(\mathrm{pH} 5.3)$. Laminarin is a polymer extracted from Laminaria digitata [20]. The DLS measurement was compatible with the previously published value of $5850 \mathrm{Da}$ [21] that was used for further calculations.

The reducing sugars were detected according to the method of Somogyi [22,23], with glucose as a standard. Enzyme and substrate blanks were performed. The katal is defined as the enzyme activity catalyzing the formation of $1 \mathrm{~mol}$ glucose equivalent per sec.

\section{Electrophoresis}

SDS-PAGE (12\% acrylamide) was performed according to Laemmli [19] and gels were stained with Colloidal Coomassie Blue
[24]. After scanning, densitometry was measured with the GelAnalyzer2010 software (http://www.gelanalyzer.com).

\section{Results}

\section{Protein production}

\section{Endoglucanase}

Initial production assays after cloning in pHGWA plasmid (adding a His-Tag to the N-ter of the cloned protein) and E. coli BL21 (DE3) resulted in the formation of inclusion bodies. Cloning in pHNGWA plasmid (adding a His-tagged NusA to the N-ter of the cloned protein) and expression in E. coli BL21(DE3) were then performed. They allowed obtention of a low amount of soluble protein, but thrombin did not properly cleave resulting chimeric protein, probably due to steric hindrance. Cloning the gene in pHGWA plasmid and transformation in Arctic Express resulted in the production of a significant amount of soluble endoglucanase, as determined by SDS-PAGE analysis of soluble proteins from bacterial lysate (Fig. 1A, lane L). Following the kit purification procedure, chaperone Cpn60 always co-purified with the endoglucanase.

\section{Viral MP}

Production of this protein in E. coli pREP4 M15 resulted in inclusion bodies [16]. The use of Arctic Express allowed the production of soluble protein (Fig. 1E, lane L), contaminated by Cpn60. However, a fraction of the synthesized MP was still in inclusion bodies (data not shown).

\section{Wash protocols}

Several assays were performed with bacterial lysate containing endoglucanase to separate $\mathrm{Cpn60}$ from the endoglucanase. As expected, bacterial lysate loaded onto Ni-TED columns and eluted according to manufacturer's instructions resulted in endoglucanase contaminated by Cpn60 (Fig. 1A, lane 1).

Initial purification washes were performed with the LEW $1 \times$ kit buffer (Fig. 1A, lane 1) or with a classical buffer system consisting of concentrated $\mathrm{NaCl}(0.5$ or $1 \mathrm{M})$ supplemented with respectively 10 or $20 \mathrm{mM}$ imidazole (Fig. $1 \mathrm{~A}$, lanes 2 and 3 ). In all of these assays, endoglucanase was highly contaminated by Cpn60.

The second attempts to eliminate $C p n 60$ consisted of washes by $\mathrm{KCl}$ containing buffers (Fig. 1B). Buffered $\mathrm{KCl}$ supplemented with ATP and $\mathrm{MgCl}_{2}$ was not able to remove bound chaperones (Fig. 1B, lane 1). Buffered $\mathrm{KCl}$ was more efficient but endoglucanase was still contaminated by the Cpn60 (Fig. 1B, lane 4). In order to check if chaperone-endoglucanase interactions could be destabilized by conformational transitions due to reaction product or substrate, either glucose or laminarin were added to buffered $\mathrm{KCl}$ (Fig. 1B, lanes 2 and 3). Best results were obtained with the $\mathrm{KCl} /$ laminarin buffer or buffered $\mathrm{KCl}$ (Fig. 1B, lanes 3 and 4). Despite this improvement, the enzyme was still not pure and its specific activity decreased compared to the enzyme purified with LEW 
$1 \times$ (data not shown), suggesting either enzyme denaturation, tight binding of laminarin or glucose-induced inhibition, despite following dialysis/concentration step.

In a third protocol, we examined wether urea at subdenaturing concentration could help purification. Chaotropic agents have been used to destabilize Cpn60 [25] or to solubilize inclusion bodies [26]. We compared washes with the kit buffer (Fig. 1C, lane 1), Tris buffer containing $25 \mathrm{mM}$ imidazole (Fig. 1C, lane 2) as well as three wash buffers containing urea (Fig. 1C, lanes 3, 4 and 5). Column wash with Tris/imidazole allowed increasing purity of endoglucanase (Fig. 1C, lane 2), but the best result was obtained with urea $2 \mathrm{M} /$ Tris $20 \mathrm{mM} \mathrm{pH} 6.8$ buffer (Fig. 1C, lane 3). The addition of $\mathrm{MgCl}_{2} / \mathrm{ATP}$ (Fig. 1C, lane 4) or $\mathrm{MgCl}_{2} / \mathrm{ATP} /$ imidazole (Fig. 1C, lane 5) did not improve purity.

A fourth series of assays consisted in measuring the minimal urea concentration necessary to eliminate Cpn60. By densitometric estimation, a $1 \mathrm{M}$ urea wash eliminated approximately $95 \%$ of Cpn60 (Fig. 1D, lane 2), compared with LEW $1 \times$ wash (Fig. 1D, lane 1). With $1.5 \mathrm{M}$ urea (Fig. 1D, lane 3) wash, approximately $98 \%$ of Cpn60 was eliminated. Lastly, with a $2 \mathrm{M}$ urea wash Cpn60 was no longer detectable (Fig. 1D, lane 4).

It was then checked if the best protocol described above could be applied to other protein. Fig. 1E shows results obtained by applying purification without or with urea wash for Movement Protein from GFLV. Wash with LEW $1 \times$ did not produce pure MP (Fig 1E, lane 2). However, although the protein was not pure (Fig 1E, lane 3), urea $2 \mathrm{M} /$ Tris $20 \mathrm{mM}$ pH 6.8 buffer eliminated Cpn60.

\section{Enzyme activity}

Purification of the same quantity of total proteins (same lysate volume, same concentration) was performed according to the five conditions described in Fig. 1C and Table 1. Protein concentration and enzymatic activity were measured for the purified endoglucanase. The highest protein yield after IMAC was obtained with LEW $1 \times$ wash (Table 1 , line 1 ), but densitometric measurements on SDS-PAGE estimated that around $55 \%$ of the eluted proteins were Cpn60 (Fig. 1C, lane 1). The enzyme activity was measured using laminarin as a substrate and the highest specific activity was with enzyme washed with urea $2 \mathrm{M}$ /Tris $20 \mathrm{mM}$ pH 6.8 buffer (Table 1, line 3). However, Tris buffer containing $25 \mathrm{mM}$ imidazole also led to a purified material with high specific activity (Table 1 , line 2). Total activity was highest following purification with wash buffers containing urea (Table 1, lines 3, 4 and 5), whereas LEW $1 \times$ and Tris/imidazole (Table 1, lines 1 and 2 ) led to a loss of around $10-15 \%$ of total activity.
Taken together, all these results indicate that the most efficient wash buffer to eliminate $\mathrm{Cpn} 60$ and to recover a high specific activity is $2 \mathrm{M}$ urea, Tris $20 \mathrm{mM} \mathrm{pH} 6.8$.

\section{DLS measurements}

In order to characterize the mechanisms of Cpn60 release from the proteins of interest, DLS measurements were undertaken with the endoglucanase. After a wash with either LEW $1 \times$ or urea $2 \mathrm{M} /$ Tris $20 \mathrm{mM} \mathrm{pH} 6.8$ buffer, hydrodynamic diameters of the eluted proteins were measured (Fig. 2). Large objects with $12 \mathrm{~nm}$ diameter were observed when the IMAC column was washed with LEW $1 \times$ (Fig. 2, short dashed line). The size of these objects is compatible with the size of a Cpn60 tetradecamer [27]. Smaller objects with $4.5 \mathrm{~nm}$ diameter were found when resin was washed with urea containing buffer (Fig. 2, long dashed line). Eluate from the column washed with LEW $1 \times$ was then dialyzed against urea $2 \mathrm{M} /$ Tris $20 \mathrm{mM}$ pH 6.8 buffer, and DLS measurement was performed. Objects of $10.1 \mathrm{~nm}$ diameter were detected (Fig. 2, plain line), but no small size objects were observed. Either the DLS measurement is not sensitive enough, or more likely because endoglucanase has a tendency to remain bound to chaperone [28] while on resin, the buffer flow pulls down Cpn60. Nevertheless, the decrease in size of the measured object is compatible with a decrease of the hydrodynamic radius of $\mathrm{Cpn} 60$ that occurs at $2 \mathrm{M}$ urea [27]. Moreover, in absence of urea, the polydispersity index (PDI) was only 0.45 , while it increased to 0.7 after dialysis against $2 \mathrm{M}$ urea. These results are compatible with a partial denaturation of Cpn60 that allows release of the endoglucanase, at least on IMAC.

\section{Discussion}

Contamination of recombinant proteins by chaperones is a common problem when using E. coli [29]. It is even more acute when using strains such as Arctic Express, this contamination usually being considered as irreversible (cf scientific forums such as ResearchGate for example). However protocols to release the protein of interest from chaperones exist. For example, a recombinant tyrosine kinase was purified by washing IMAC column with $\mathrm{MgCl}_{2}$ / ATP and $300 \mathrm{mM} \mathrm{KCl} \mathrm{[15].} \mathrm{Some} \mathrm{authors} \mathrm{tailored} \mathrm{the} \mathrm{protein} \mathrm{to} \mathrm{be}$ produced by minimizing its predicted interaction with DnaK and, prior to final elution they washed the column with a mix of $\mathrm{MgCl}_{2}$ / ATP and soluble denatured proteins from $E$. coli [14]. Other authors performed a simple wash with denatured bacterial proteins [29].

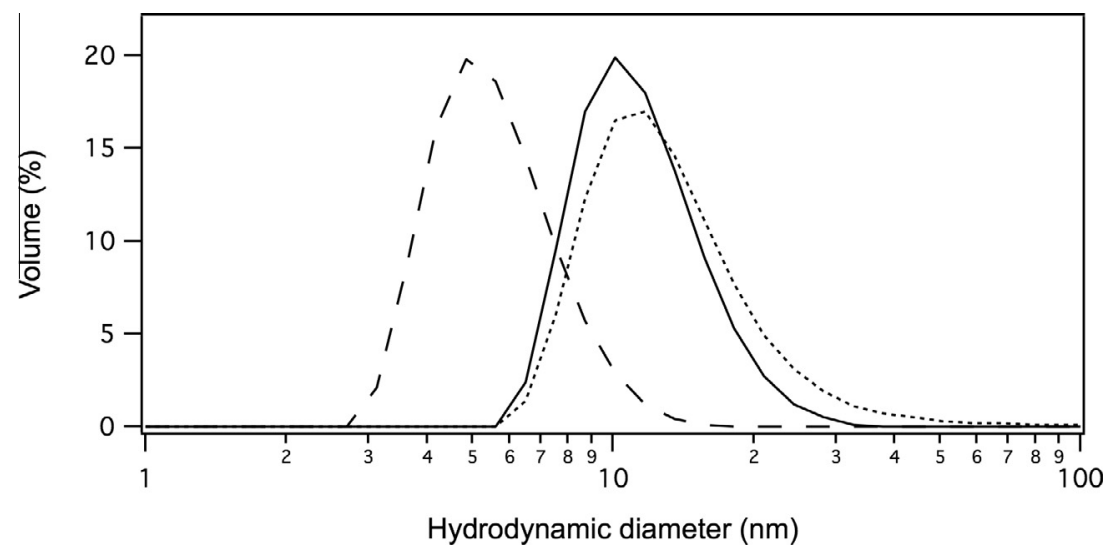

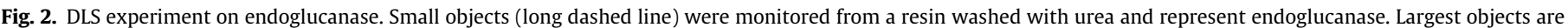

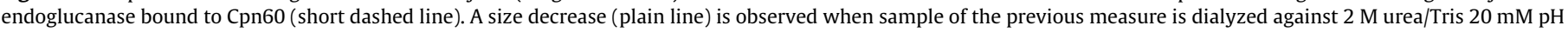
6.8 buffer. 
In parallel, numerous studies addressing the dynamics of GroEL (homologous to Cpn60 or DnaK) or its interaction with GroES and neosynthesized proteins have been published. Horowitz et al. [25] showed that chaotropic agents such as urea or guanidinium chloride can expose hydrophobic regions of $\mathrm{Cpn60}$ (homologous to $E$. coli GroEL). Addition of $\mathrm{MgCl}_{2}$ /ATP facilitated this exposure.

Binding of human ornithine transcarbamylase (OTC) to GroEL [30] showed that the chaperone is necessary for correct folding of the protein. To release OTC from GroEL, both GroES and $\mathrm{MgCl}_{2}$ / ATP are necessary. The authors found that hydrophobic aminoacids of the apical region of GroEL are involved in the binding of OTC. Moreover, allosteric movements as well as monomerization or oligomerization are involved in binding or release of proteins [30-32]. Taken together, these reports suggest that addition of $\mathrm{MgCl}_{2}$ /ATP and GroES, by inducing conformational modifications, release loosely bound proteins. However, release of deeply buried polypeptides necessitates a disassembly of oligomeric GroEL.

Production in the E. coli BL21 strain of an endoglucanase and a viral movement protein resulted in formation of inclusion bodies. Expression of these proteins in Arctic Express strain allowed soluble proteins production, but after IMAC purification, the proteins were contaminated with large amounts of Cpn60. To eliminate this contaminant, several different wash assays, based on data from the literature and our own experience, were tested. It should first be noted that the His-Tag was bound to the resin metal, suggesting that it was located outside the complex. Washes using a combination of 0.5 to $1 \mathrm{M} \mathrm{NaCl}$ in the presence of low imidazole concentration (10 or $20 \mathrm{mM}$; Fig. $1 \mathrm{~A}$, lanes 2 and 3 ), classically used to eliminate non-specifically bound proteins, slightly improved the purity but were unable to eliminate the chaperone. Combining salt with enzyme substrate or product did not result in improved purification, except with buffered $\mathrm{KCl}$ (Fig. 1B, lane 4). Contamination was maintained upon wash with salts suggesting that hydrophobic interactions occurred between both proteins [30].

In a third series of assays, the column was washed with ureacontaining buffers, supplemented or not by $\mathrm{MgCl}_{2} / \mathrm{ATP}$ [25]. Addition of urea, at a sub-denaturing concentration, was sufficient to detach chaperone and enzymes. Adding $\mathrm{MgCl}_{2} / \mathrm{ATP}$ and/or imidazole did not improve purity. Adding $2 \mathrm{M}$ of urea to the LEW $1 \mathrm{x}$ resulted in endoglucanase still highly contaminated with Cpn60 (supplementary data), confirming the hydrophobic nature of the interaction between Cpn60 and recombinant proteins. Increasing urea concentrations were assessed to determine the optimal concentration necessary to detach Cpn60. A concentration of $1 \mathrm{M}$ urea was quite efficient; Cpn60 was still visible with $1.5 \mathrm{M}$ urea but was no longer detectable at $2 \mathrm{M}$. However, it is likely that the most efficient urea concentration depends on the protein to purify and should be checked accordingly. DLS experiments showed that the hydrodynamic radius of Cpn60 decreased in the presence of urea [27]. This modification results in a facilitated release of bound proteins as experimentally observed.

Taken together, these results indicate that chaperone and enzyme form aggregates that are dissociated by the presence of low concentrations of a chaotropic agent, a protocol already described for mild solubilization of inclusion bodies [33,34]. It is thus likely that the complexes form soluble aggregates composed of native as well as partially folded proteins [35]. As a consequence, obtaining large amounts of purified soluble enzyme is not sufficient if the native 3D structure and activity are not maintained. We thus measured specific activities and the total activities of purified enzyme. The results (Table 1 ) show that the protein quantity and the highest activity were obtained with a urea wash.

The negative or positive roles of urea on protein folding are abundantly documented as well as its effects against protein aggregation [31,36,37]. From the data presented above, it can be hypothesized that urea acts as a mild destabilizer of Cpn60, releasing it from the His-tagged proteins bound to the resin but without denaturing them.

\section{Conclusion}

In this article we developed a method to release Cpn60, a constitutively expressed chaperone by the Arctic Express E. coli strain from the recombinant proteins of interest. We showed that a subdenaturing chaotropic concentration ( $2 \mathrm{M}$ ) of urea is sufficient to eliminate Cpn60 without affecting the recovery of the protein of interest. We demonstrated that an endoglucanase was fully active after this treatment. We successfully applied this protocol to another protein, suggesting that the procedure is robust. The protocol described here will greatly improve purification of numerous proteins produced in the Arctic Express system.

\section{Acknowledgments}

We warmly thank Dr Bernard Lorber (IBMC, Strasbourg) for his help with the DLS measurements. We are indebted towards Dr Philippe Hugueney for his precious help with Gateway cloning. We are grateful to Dr Christophe Ritzenthaler (CNRS, IBMP, Strasbourg) for critical reading of this manuscript and to Dr David Hicks (CNRS, INCI, Strasbourg) for language correction.

This work was supported by Santé des Plantes et Environnement Department (INRA) and by a grant from École Doctorale de Strasbourg (ED 414, Sciences de la Vie et de la Santé) to LB.

\section{Appendix A. Supplementary data}

Supplementary data associated with this article can be found, in the online version, at http://dx.doi.org/10.1016/j.pep.2015.01.009.

\section{References}

[1] R. Assenberg, P.T. Wan, S. Geisse, L.M. Mayr, Advances in recombinant protein expression for use in pharmaceutical research, Curr. Opin. Struct. Biol. 23 (3) (Jun. 2013) 393-402.

[2] D. Busso, B. Delagoutte-Busso, D. Moras, Construction of a set Gateway-based destination vectors for high-throughput cloning and expression screening in Escherichia coli, Anal. Biochem. 343 (2) (Aug. 2005) 313-321.

[3] W. Peti, R. Page, Strategies to maximize heterologous protein expression in Escherichia coli with minimal cost, Protein Expr. Purif. 51 (1) (Jan. 2007) 1-10.

[4] P.H. Bessette, F. Aslund, J. Beckwith, G. Georgiou, Efficient folding of proteins with multiple disulfide bonds in the Escherichia coli cytoplasm, Proc. Natl. Acad. Sci. U.S.A. 96 (24) (Nov. 1999) 13703-13708.

[5] M. Lebendiker, T. Danieli, Production of prone-to-aggregate proteins, FEBS Lett. 588 (2) (Jan. 2014) 236-246.

[6] G. Calloni, T. Chen, S.M. Schermann, H. Chang, P. Genevaux, F. Agostini, G.G. Tartaglia, M. Hayer-Hartl, F.U. Hartl, DnaK functions as a central hub in the E. coli chaperone network, Cell Rep. 1 (3) (Mar. 2012) 251-264.

[7] A. Dickson, C.L. Brooks, Quantifying chaperone-mediated transitions in the proteostasis network of E. coli, PLoS Comput. Biol. 9 (11) (Nov. 2013) e1003324.

[8] G.J. Gopal, A. Kumar, Strategies for the production of recombinant protein in Escherichia coli, Protein J. 32 (6) (Aug. 2013) 419-425.

[9] R. Levy, R. Weiss, G. Chen, B.L. Iverson, G. Georgiou, Production of correctly folded Fab antibody fragment in the cytoplasm of Escherichia coli trxB gor mutants via the coexpression of molecular chaperones, Protein Expr. Purif. 23 (2) (Nov. 2001) 338-347.

[10] A. de Marco, E. Deuerling, A. Mogk, T. Tomoyasu, B. Bukau, Chaperone-based procedure to increase yields of soluble recombinant proteins produced in $E$. coli, BMC Biotechnol. 7 (2007) 32.

[11] D. Hartinger, S. Heinl, H.E. Schwartz, R. Grabherr, G. Schatzmayr, D. Haltrich, W.-D. Moll, Enhancement of solubility in Escherichia coli and purification of an aminotransferase from Sphingopyxis sp. MTA144 for deamination of hydrolyzed fumonisin B1, Microb. Cell Fact. 9 (1) (2010) 62.

[12] L. da, S. Pinto, R.A. Gonçales, F.R. Conceição, P.F. Knabah, S. Borsuk, V.F. Campos, F.V. Arruda, F.P.L. Leite, Stability, oviposition attraction, and larvicidal activity of binary toxin from Bacillus sphaericus expressed in Escherichia coli, Appl. Microbiol. Biotechnol. 95 (5) (Sep. 2012) 1235-1241.

[13] S.M. Thayil, N. Morrison, N. Schechter, H. Rubin, P.C. Karakousis, The Role of the Novel Exopolyphosphatase MT0516 in Mycobacterium tuberculosis Drug Tolerance and Persistence, PLoS ONE 6 (11) (Nov. 2011) e28076. 
[14] D.V. Rial, E.A. Ceccarelli, Removal of DnaK contamination during fusion protein purifications, Protein Expr. Purif. 25 (3) (Aug. 2002) 503-507.

[15] R.E. Joseph, A.H. Andreotti, Bacterial expression and purification of interleukin2 tyrosine kinase: single step separation of the chaperonin impurity, Protein Expr. Purif. 60 (2) (Aug. 2008) 194-197.

[16] C. Ritzenthaler, M. Pinck, L. Pinck, Grapevine fanleaf nepovirus P38 putative movement protein is not transiently expressed and is a stable final maturation product in vivo, J. Gen. Virol. 76 (Pt 4) (Apr. 1995) 907-915.

[17] C. Ritzenthaler, A. Schmit, P. Michler, C. Stussi-Garaud, L. Pinck, Grapevine fanleaf nepovirus P38 putative movement protein is located on tubules in vivo, Mol. Plant Microbe Interact. 8 (3) (Jan. 1995) 379-387.

[18] E. Vigne, J. Gottula, C. Schmitt-Keichinger, V. Komar, L. Ackerer, L. Belval, L. Rakotomalala, O. Lemaire, C. Ritzenthaler, M. Fuchs, A strain-specific segment of the RNA-dependent RNA polymerase of grapevine fanleaf virus determines symptoms in Nicotiana species, J. Gen. Virol. 94 (Pt 12) (Dec. 2013) 2803-2813.

[19] U.K. Laemmli, Cleavage of structural proteins during the assembly of the head of bacteriophage T4, Nature 227 (5259) (Aug. 1970) 680-685.

[20] T.-Y. Hong, C.-W. Cheng, J.-W. Huang, M. Meng, Isolation and biochemical characterization of an endo-1,3-beta-glucanase from Streptomyces sioyaensis containing a C-terminal family 6 carbohydrate-binding module that binds to 1,3-beta-glucan, Microbiology 148 (Pt 4) (Apr. 2002) 1151-1159.

[21] Z. Pang, K. Otaka, T. Maoka, K. Hidaka, S. Ishijima, M. Oda, M. Ohnishi, Structure of beta-glucan oligomer from laminarin and its effect on human monocytes to inhibit the proliferation of U937 cells, Biosci. Biotechnol. Biochem. 69 (3) (Mar. 2005) 553-558.

[22] M. Somogyi, Notes on sugar determination, J. Biol Chem 195 (1952) 19-23.

[23] M.J. Karvonen, O. Somersalo, A note on the determination of fructose and glucose by the Somogyi method, Ann. Med. Exp. Biol. Fenn. 30 (1) (1952) 3134.

[24] V. Neuhoff, N. Arold, D. Taube, W. Ehrhardt, Improved staining of proteins in polyacrylamide gels including isoelectric focusing gels with clear background at nanogram sensitivity using Coomassie Brilliant Blue G-250 and R-250, Electrophoresis 9 (6) (Jun. 1988) 255-262.

[25] P.M. Horowitz, S. Hua, D.L. Gibbons, Hydrophobic surfaces that are hidden in chaperonin Cpn60 can be exposed by formation of assembly-competent monomers or by ionic perturbation of the oligomer, J. Biol. Chem. 270 (4) (Jan. 1995) 1535-1542.
[26] S.M. Singh, A.K. Panda, Solubilization and refolding of bacterial inclusion body proteins, J. Biosci. Bioeng. 99 (4) (Apr. 2005) 303-310.

[27] N.A. Ryabova, V.V. Marchenkov, S.Y. Marchenkova, N.V. Kotova, G.V Semisotnov, Molecular chaperone GroEL/ES: unfolding and refolding processes, Biochem. Mosc. 78 (13) (Dec. 2013) 1405-1414.

[28] H. Taguchi, M. Yoshida, Chaperonin releases the substrate protein in a form with tendency to aggregate and ability to rebind to chaperonin, FEBS Lett. 359 (2-3) (Feb. 1995) 195-198.

[29] M. Rohman, K.J. Harrison-Lavoie, Separation of copurifying GroEL from glutathione-S-transferase fusion proteins, Protein Expr. Purif. 20 (1) (Oct. 2000) 45-47.

[30] W.A. Fenton, Y. Kashi, K. Furtak, A.L. Horwich, Residues in chaperonin GroEL required for polypeptide binding and release, Nature 371 (6498) (Oct. 1994) 614-619.

[31] A. Blennow, B.P. Surin, H. Ehring, N.F. McLennan, M.D. Spangfort, Isolation and biochemical characterization of highly purified Escherichia coli molecular chaperone Cpn60 (GroEL) by affinity chromatography and urea-induced monomerization, Biochim. Biophys. Acta 1252 (1) (Sep. 1995) 69-78.

32] M.K. Hayer-Hartl, F. Weber, F.U. Hartl, Mechanism of chaperonin action: GroES binding and release can drive GroEL-mediated protein folding in the absence of ATP hydrolysis, EMBO J. 15 (22) (Nov. 1996) 6111-6121.

[33] M.A. Speed, D.I. Wang, J. King, Specific aggregation of partially folded polypeptide chains: the molecular basis of inclusion body composition, Nat. Biotechnol. 14 (10) (Oct. 1996) 1283-1287.

[34] A.K. Patra, R. Mukhopadhyay, R. Mukhija, A. Krishnan, L.C. Garg, A.K. Panda, Optimization of inclusion body solubilization and renaturation of recombinant human growth hormone from Escherichia coli, Protein Expr. Purif. 18 (2) (Mar. 2000) 182-192.

[35] A. Haacke, G. Fendrich, P. Ramage, M. Geiser, Chaperone over-expression in Escherichia coli: apparent increased yields of soluble recombinant protein kinases are due mainly to soluble aggregates, Protein Expr. Purif. 64 (2) (Apr. 2009) 185-193.

[36] G. Orsini, M.E. Goldberg, The renaturation of reduced chymotrypsinogen A in guanidine $\mathrm{HCl}$. Refolding versus aggregation, J. Biol. Chem. 253 (10) (May 1978) 3453-3458.

[37] H. Hamada, T. Arakawa, K. Shiraki, Effect of additives on protein aggregation, Curr. Pharm. Biotechnol. 10 (4) (Jun. 2009) 400-407. 